\title{
Targeting Vascular NADPH Oxidase 1 Blocks Tumor Angiogenesis through a PPARa Mediated Mechanism
}

\author{
Sarah Garrido-Urbani ${ }^{1}$, Stephane Jemelin ${ }^{1}$, Christine Deffert ${ }^{1}$, Stéphanie Carnesecchi ${ }^{1,2}$, Olivier Basset ${ }^{1}$, \\ Cédric Szyndralewiez ${ }^{3}$, Freddy Heitz ${ }^{3}$, Patrick Page ${ }^{3}$, Xavier Montet ${ }^{4}$, Liliane Michalik ${ }^{5}$, Jack Arbiser ${ }^{6}$, \\ Curzio Rüegg ${ }^{7}$, Karl Heinz Krause', Beat Imhof ${ }^{1 *}$
}

1 Department of Pathology and Immunology, Centre Médical Universitaire, University of Geneva, Geneva, Switzerland, 2 Department of Pediatrics, Centre Médical Universitaire, University of Geneva, Geneva, Switzerland, 3 GenKyoTex S.A., Geneva, Switzerland, 4 Department of Physiology and Metabolism, Centre Médical Universitaire, University of Geneva, Geneva, Switzerland, $\mathbf{5}$ Center for Integrative Genomics, University of Lausanne, Lausanne, Switzerland, $\mathbf{6}$ Department of Dermatology, Emory University School of Medicine, Atlanta, Georgia, United States of America, 7 Department of Medicine, Faculty of Science, University of Fribourg, Fribourg, Switzerland

\begin{abstract}
Reactive oxygen species, ROS, are regulators of endothelial cell migration, proliferation and survival, events critically involved in angiogenesis. Different isoforms of ROS-generating NOX enzymes are expressed in the vasculature and provide distinct signaling cues through differential localization and activation. We show that mice deficient in NOX1, but not NOX2 or NOX4, have impaired angiogenesis. NOX1 expression and activity is increased in primary mouse and human endothelial cells upon angiogenic stimulation. NOX1 silencing decreases endothelial cell migration and tube-like structure formation, through the inhibition of PPAR $\alpha$, a regulator of NF-KB. Administration of a novel NOX-specific inhibitor reduced angiogenesis and tumor growth in vivo in a PPAR $\alpha$ dependent manner. In conclusion, vascular NOX1 is a critical mediator of angiogenesis and an attractive target for anti-angiogenic therapies.
\end{abstract}

Citation: Garrido-Urbani S, Jemelin S, Deffert C, Carnesecchi S, Basset O, et al. (2011) Targeting Vascular NADPH Oxidase 1 Blocks Tumor Angiogenesis through a PPAR $\alpha$ Mediated Mechanism. PLoS ONE 6(2): e14665. doi:10.1371/journal.pone.0014665

Editor: Stefan Wölfl, Universität Heidelberg, Germany

Received June 16, 2010; Accepted January 11, 2011; Published February 7, 2011

Copyright: (C) 2011 Garrido-Urbani et al. This is an open-access article distributed under the terms of the Creative Commons Attribution License, which permits unrestricted use, distribution, and reproduction in any medium, provided the original author and source are credited.

Funding: This work was supported by the Swiss Cancer League, KPS-OCS 01812-12-2005 and by the Swiss National Science Foundation, FNS-310030-120184. These funders had no role in study design, data collection and analysis, decision to publish, or preparation of the manuscript. This study was also funded by GenKyoTex S.A. as employer of some of the authors. This funder was implicated in study design, data collection and analysis, decision to publish, or preparation of the manuscript.

Competing Interests: A patent is pending on GKT136901 with PP as inventor and GenKyoTex as owner of the patent. PP, CS and K-HK own shares of GenKyoTex. A patent is pending on fulvene-5, with JLA as inventor and Emory University as owner of the patent. This does not alter the authors' adherence to all the PLoS ONE policies on sharing data and materials.

*E-mail: beat.imhof@unige.ch

\section{Introduction}

Angiogenesis is a complex process occurring in physiological situations such as embryogenesis and wound repair, and contributes to pathological conditions such as diabetes, psoriasis, arthritis and cancer. Angiogenesis is a critical determinant of cancer progression. In its absence, tumors are unable to grow beyond the size of microscopic lesions and persist as dormant, nonexpanding nodules $[1,2]$. Tumor cells, stromal cells and infiltrating bone marrow-derived cells can initiate angiogenesis through a process called angiogenic switch in which secretion of proangiogenic factors is increased and/or production of endogenous anti-angiogenic factors is reduced [3,4]. Angiogenic vessels are mostly formed by sprouting of endothelial cells from the existing vasculature. This process involves degradation of the surrounding matrix, cell proliferation, migration, differentiation, and tube formation [5]. Inhibition of angiogenesis has recently been introduced in the clinics as novel therapeutic option to block cancer progression [6].

$\mathrm{NADPH}$ oxidases are enzymes that produce reactive oxygen species (ROS). Depending on concentration and sub-cellular localization, ROS can mediate a variety of cellular functions, including pathogen killing, cell migration, proliferation and differentiation (for review [7]). The NADPH oxidase (NOX) family of proteins consists of seven isoforms (NOX1-5 and DUOX 1-2), which transport electrons across membranes, thereby reducing oxygen into superoxide. Depending on the isoform, these catalytic transmembrane proteins form a complex with $\mathrm{p} 22^{\text {phox }}$ and the cytoplasmic subunits $\mathrm{p} 67^{\text {phox }} / \mathrm{NOXO1}, \mathrm{p} 47^{\text {phox }} /$ NOXA1, p40 phox and Racl/2 [7]. The NOX1 isoform is expressed in epithelial cells, retinal pericytes, osteoclasts, vascular smooth muscle and endothelial cells [8-16]. While increased NOX1 expression has been reported in cases of colon cancer [17], it has been suggested that this may correlate with inflammation rather than tumorigenesis [18,19]. However, experimental overexpression of NOX1 in fibroblasts or carcinoma cells induced an angiogenic switch mediated by the increased production of VEGF and MMPs [20]. Moreover NOXl has been shown to regulate apoptosis and morphogenesis of sinusoid endothelial cells in vitro [16].

The nuclear hormone receptors peroxisome proliferatoractivated receptors (PPAR) dimerize with the retinoid $\mathrm{X}$ receptor. Upon activation by lipids, this complex regulates gene transcription by binding to peroxisome proliferator-responsive elements. PPAR $\alpha$, a member of the family, was shown to mediate antiinflammatory activity through inhibition of the transcription factor 
$\mathrm{NF}-\kappa \mathrm{B}$. In the vascular system, PPAR $\alpha$ inhibits NF- $\kappa \mathrm{B}$ transactivation either by direct interaction with the $\mathrm{p} 65$ subunit or by upregulation of $\mathrm{I}-\kappa \mathrm{B}$, the $\mathrm{NF}-\kappa \mathrm{B}$ inhibitory subunit [21,22]. In different tumor models, activation of PPAR $\alpha$ by agonists blocks tumor growth and angiogenesis by reducing production of proangiogenic factors such as VEGF or epoxyeicosatrienoic acids [23-25]. In human endothelial cells, PPAR $\alpha$ activators also inhibit cytokine-induced expression of adhesion molecules and chemokines [26].

In this study, we analyzed the role of NOX1 in human and mouse angiogenesis and observed an increased expression and activity of NOX1 during the angiogenic switch. Furthermore, blood vessel formation in NOX1-deficient mice was dramatically reduced in response to angiogenic factors and in tumors. NOX1 deficiency also lead to reduced endothelial cell migration and reduced formation of tube-like structures. We analyzed the mechanism by which NOX1 regulates angiogenesis and showed that NOX1 down-regulates expression and activity of the antiinflammatory and anti-angiogenic nuclear receptor PPAR $\alpha$.

\section{Results}

\section{NOX1-deficient mice show impaired angiogenesis}

In order to test whether NOX-dependent ROS production participates in blood vessel formation, we performed in vivo Matrigel angiogenesis assays using mice deficient for different NOX isoforms. Matrigel was preloaded with the angiogenic factor bFGF and implanted subcutaneously into wild type (WT) or NOX-deficient mice. Subcutaneous Matrigel plug vascularization quantified by X-Ray-based computer tomography in animals deficient for NOX2 or NOX4 had angiogenic responses indistinguishable from WT mice. By contrast, Matrigel plug vascularization was reduced by $47 \% \pm 7.6$ and $65 \% \pm 13.2$ in NOX1 knockout and NOX1/2 double knockout animals respectively, as compared to WT mice (Figure 1a). This difference is noticeable on macroscopic images of Matrigel plugs following excision (Figure 1b). Immunostaining of plugs with the vascular marker PECAM-1 demonstrated reduced PECAM-1-positive areas in NOX1-and NOX1/2-deficient mice $(56 \% \pm 2$ and $46 \% \pm$ 3 respectively) compared to WT animals (Figure 1c,d). Remarkably, plugs in NOX1-and NOX1/2-deficient mice were lacking large vessels while the number of small vessels significantly increased (Figure 1e).

From these results, we conclude that NOX1 is essential for bFGF-induced angiogenesis.

\section{NOX1 expression and activity are up-regulated by proangiogenic factors}

To determine whether the aberrant angiogenesis observed in NOX1-deficient mice was due to impaired endothelial cell function; we studied the effect of NOX1 inhibition on mouse lung endothelial cells (MLEC) [27] (Figure S1), murine thymic endothelioma (tEnd) cells and primary human umbilical veinderived endothelial cells (HUVEG). We first studied the expression level of NOX1 in these cells under basal conditions and in response to stimulation with the angiogenic factors VEGF or $\mathrm{bFGF}$ at $20 \mathrm{ng} / \mathrm{ml}$ for 3 hours. Quantitative real-time PGR revealed 2-3 fold up-regulation of NOX1 mRNA expression in all endothelial cells after angiogenic stimulation (Figure 2a-c). Expression of NOX4 and NOX2 did not change upon VEGF or bFGF stimulation (data not shown). While endothelial NOX4 expression level was high, NOX2 was found to be very low.

Next, we analyzed ROS production in murine and human endothelial cells in response to VEGF and bFGF stimulation. As expected, these factors increased intracellular ROS levels (Figure $2 \mathrm{~g}-\mathrm{i}$ ), while in NOX1-deficient MLEC, ROS production in response to VEGF or bFGF stimulation was absent or severely compromised (Figure 2d,g). This is in contrast to NOX4 deficiency, which did not affect ROS production, induced by VEGF or bFGF. These data were consistent with observed deficient ROS production by endothelial cells following NOX1 silencing (Figure 2i and data not shown). Additionally, cells treated with the pharmacological NOX inhibitor GKT136901 did not induce ROS after VEGF or bFGF stimulation (Figure 2d-i). The specific NADPH oxidase inhibitor GKT136901 was identified by screening more than 130,000 molecules [28]. In a NOX subunit specific cell-free system [29,30], GKT136901 inhibits NOX1 with high affinity $(\mathrm{Ki}=160 \pm 10 \mathrm{nM})$, similar to the irreversible flavoprotein inhibitor Diphenyliodonium (DPI; Ki $=70 \pm 10 \mathrm{nM}$ ) (Figure 3a). However, DPI shows the same potency on NOX4 $(\mathrm{Ki}=70 \mathrm{nM}), \quad \mathrm{NOX} 2(\mathrm{Ki}=70 \mathrm{nM})$ and xanthine oxidase $(\mathrm{Ki}=50 \mathrm{nM})$. In contrast, GKT136901 is more specific for NOX1 and NOX4 with a ten-fold lower potency on NOX2 $(\mathrm{Ki}=$ $1530 \pm 90 \mathrm{nM}$ ) and almost no affinity for xanthine oxidase $(\mathrm{Ki}>100 \mu \mathrm{M})$ (Figure $3 \mathrm{~b}$ and Figure S2). Moreover, GKT136901 completely inhibits oxidase activity of NOX1 and NOX4 but has only a partial effect on NOX2 (Figure S2). In order to demonstrate the specificity of GKT136901 for NOX enzymes, a pharmacological profiling of 135 different targets was performed including ROS producing and redox-sensitive enzymes [31]. GKT136901 at $10 \mu \mathrm{M}$ showed low or no inhibition demonstrating the high degree of specificity of this compound (Table S1).

Taken together, the results obtained with NOX1 deficient cells and the inhibitor GKT136901 demonstrate that NOX1 is responsible for ROS production in endothelial cells stimulated with the pro-angiogenic factors VEGF or bFGF.

NOX1 mediates endothelial cell migration and sprouting

Angiogenesis requires endothelial cell proliferation, sprouting and migration [5]. To identify the NOX1-dependent step in angiogenesis, we performed different in vitro functional assays. Cell proliferation was not altered in NOX1-deficient MLEG, nor in NOX1 silenced cells (data not shown). However, cell migration and tube formation of MLEC from NOX1-deficient animals was significantly reduced as compared to WT cells (Figure 4a, d). We also observed an inhibition of endothelial cell migration and tube formation in MLEC treated with the NOX1 inhibitor GKT136901 (Figure 4) and NOX-dependent ROS blocking agents (Figure S3) [32,33]. Furthermore, silencing of NOX1 expression using siRNA in mouse and human endothelial cells significantly reduced migration $(17 \% \pm 5.7$ and $24 \% \pm 3.8$ of migrating area reduction respectively) and formation of tube-like structures $(28 \% \pm 4.8$ and $34 \% \pm 14$ of reduction in skeleton length respectively) (Figure 4c, e and f). We did not observe any inhibition of migration or tube formation with MLEC derived from NOX4-deficient mice or with cells in which NOX4 was silenced using siRNA (Figure 4a, c, d and f).

Moreover, using a NOX1 expressing vector we observed that NOX1 overexpression (thirteen-fold increase) is sufficient to increase endothelioma cell migration and tube-like structure formation (Figure S4).

These experiments demonstrate that NOX1 is an important protein involved in migration and tube-like structure formation of endothelial cells with no detectable role in cell proliferation.

\section{NOX1 down-regulates PPAR $\alpha$ expression}

$\operatorname{PPAR} \alpha$ is a nuclear hormone receptor with anti-inflammatory functions able to block the angiogenic activity of VEGF 
A

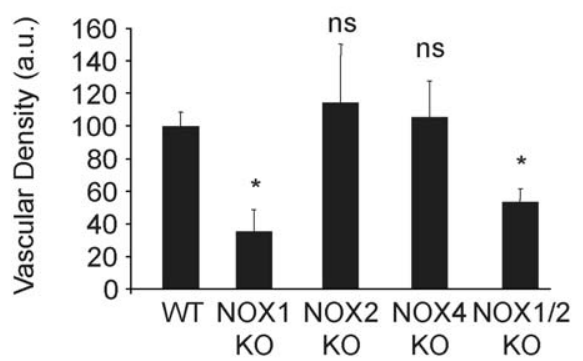

C

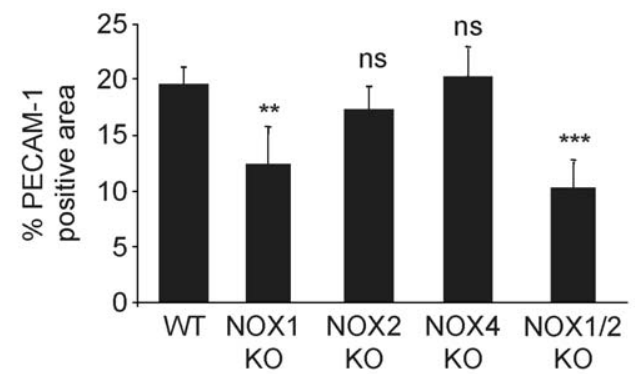

$\mathrm{E}$

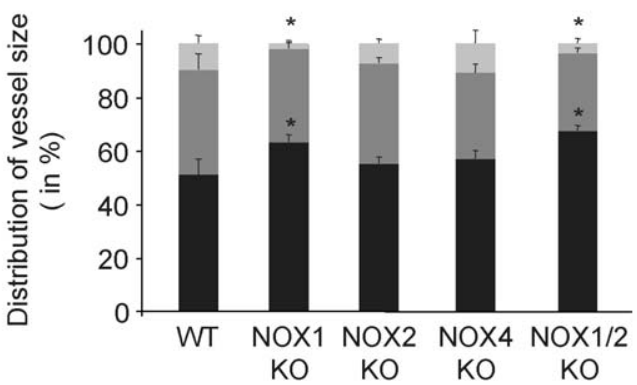

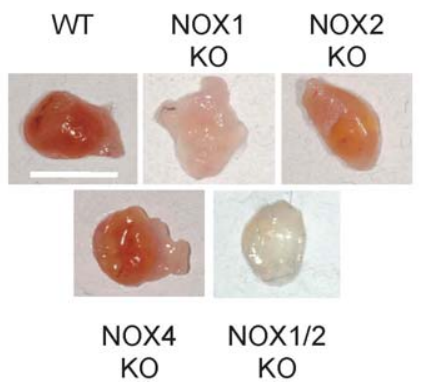

D

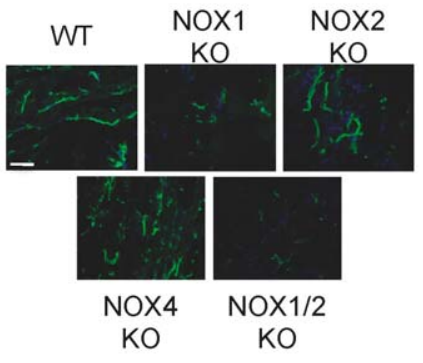

Figure 1. NOX1 deficient mice exhibit reduced angiogenic capacity. Matrigel was loaded with $500 \mathrm{ng} / \mathrm{ml} \mathrm{bFGF}$ and implanted subcutaneously into NOX deficient mice. After one week, iodinated liposomes were injected i.v. and the plugs analyzed by X-ray tomography. (a) Quantification of matrigel plug vascularization. Graph shows mean of grey density \pm s.e.m. For WT, NOX1 KO and NOX1/2 KO $n=8$ and for NOX2 KO and NOX4 KO $n=6$. (b) Photographs of excised plugs, scale bars represent $1 \mathrm{~cm}$. c. Blood vessel density in plugs from the experiment in (a). Graph shows percentage of PECAM-1 positive area \pm s.e.m. (d). Photographs of PECAM-1 immunostaining, PECAM-1 in green, nuclei in blue, scale bars represent $20 \mu \mathrm{m}$. Images were acquired with a 20x/0.5 numeric aperture lens and analyzed using LSM510 Meta confocal microscope (Carl Zeiss). e. Vessel size analysis; vessel with lumen under $20 \mu \mathrm{m}$ are considered as small (black), from 20 to 50 medium (dark grey) and over $50 \mu \mathrm{m}$ as large (light grey) \pm s.e.m. Anova $\mathrm{p}<0.01 ;{ }^{*} \mathrm{p}<0.05,{ }^{* *} \mathrm{p}<0.01,{ }^{* * *} \mathrm{p}<0.001$. doi:10.1371/journal.pone.0014665.g001

$[23,34,35]$. We observed that NOX1-deficient MLEG expressed 5-fold higher PPAR $\alpha$ compared to WT MLEC (Figure 5a), while no difference was seen with PPAR $\gamma$ expression (data not shown). This up-regulation of PPAR $\alpha$ expression was also observed in endothelial cell lines silenced for NOX1 (Figure 5a), and was dependent on PPAR $\alpha$ transactivation. Indeed, when NOX1silenced cells were incubated with the PPAR $\alpha$ antagonist GW6471, PPAR $\alpha$ up regulation was no longer observed (data not shown). This suggests that the deficiency in migration and tube formation observed in NOX1-deficient endothelial cells may depend on up-regulation of PPAR $\alpha$ expression and transcriptional activity.

To test this hypothesis, we treated NOX1-deficient MLEC with the PPAR $\alpha$ antagonist GW6471 and found that the compound restored cell migration and tube formation compared to untreated NOX1-deficient cells (Figure 5b-c). Moreover, PPAR $\alpha$-deficient endothelial cells isolated from $\operatorname{PPAR} \alpha$-deficient mice migrated more than WT endothelial cells. As expected, inhibition of NOX1 using the inhibitor GKT136901 in PPAR $\alpha$-deficient cells did not affect endothelial cell migration or invasion (data not shown).

Taken together, these results indicate that NOX1 promotes endothelial cell migration and sprouting by suppressing PPAR $\alpha$ expression and activity.

\section{NOX1 promotes NF- $\kappa B$ activation in response to angiogenic stimulation by PPAR $\alpha$ inhibition}

We then set out to further identify the vascular NOX1 signaling pathways implicated in angiogenesis. Activation of both Akt and ERK $1 / 2$ were observed following 10 minutes of stimulation with the angiogenic factor bFGF. In NOX1-deficient MLEC, Akt activation was reduced compared to WT cells, while ERK1/2 activation was unaffected (Figure S5). These results showed that NOX 1 is involved in the activation of the Akt signaling pathway in response to bFGF. Since NOX1 suppresses PPAR $\alpha$ expression, 
A

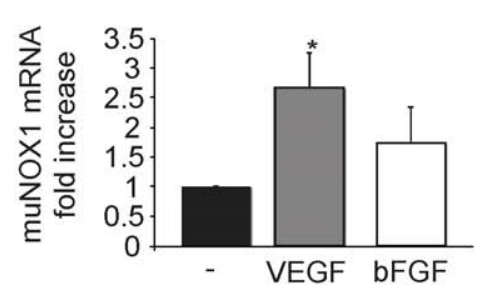

D

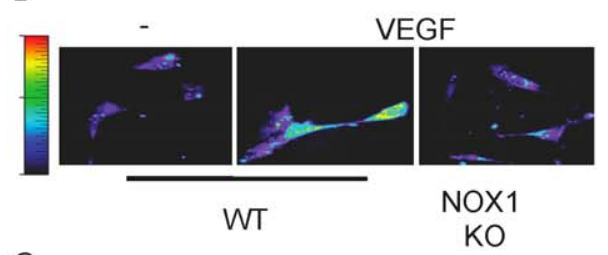

G

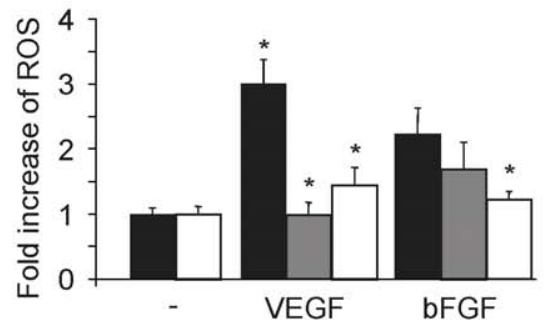

WT or Non treated cells
B

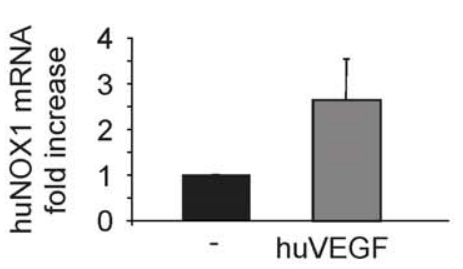

E

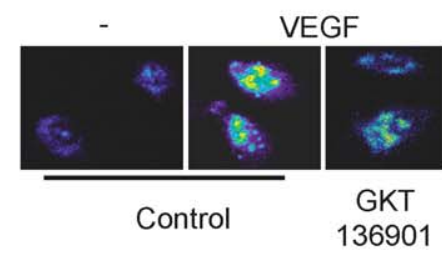

$\mathrm{H}$

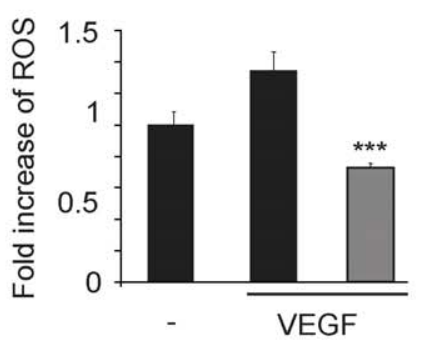

GKT136901 treated cells
C

Endothelioma cell

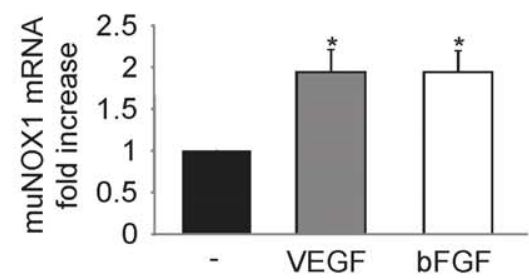

$\mathrm{F}$

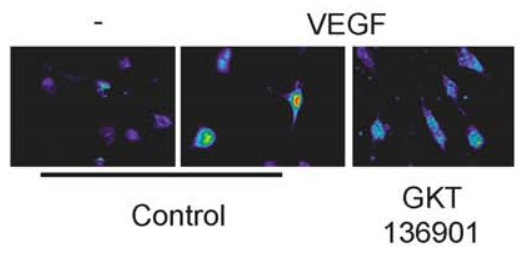

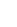

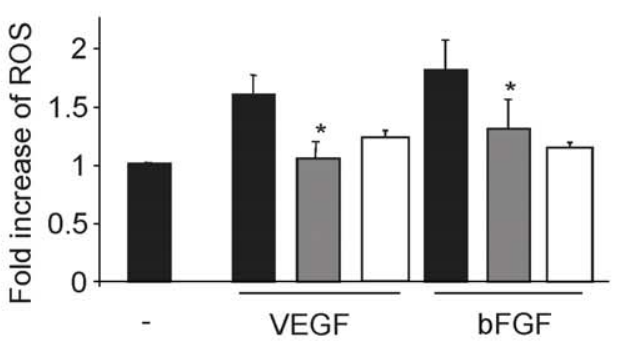

NOX1 deficient or silenced cells

Figure 2. NOX1 expression and activity is up-regulated by angiogenic stimuli. NOX1 expression was measured by quantitative real-time PCR in mouse primary lung endothelial cells (MLEC, a), HUVEC (b), mouse endothelioma cell line (c) after stimulation with VEGF or b-FGF at 20 ng/ml for 3 hours. The quantity of NOX1 mRNA was normalized to the quantity of a housekeeping gene, tubulin for mouse cells and $\beta 2$-microglobulin for human cells, \pm s.e.m, $n=3$. Activity of NOX1 was evaluated by ROS measurement using DHE substrate on MLEC (d,g), HUVEC (e, h) and mouse endothelioma (f, i). ROS production is up-regulated by VEGF and b-FGF stimulation in a NOX1-dependent manner. $g$, $h$, i. Graphs show quantification of ROS level in endothelial cells stimulated in presence or absence of VEGF or b-FGF. g. MLEC WT (black bar), MLEC WT + GKT136901 (grey bar), MLEC NOX1KO (white bar). h. HUVEC untreated (black bar) or treated with GKT136901 at $10 \mu \mathrm{M}$ (grey bar). i. Mouse endothelioma cell line untreated (black bar), treated with GKT136901 at $10 \mu \mathrm{M}$ (grey bar), treated with NOX1 siRNA (white bar). Results are expressed in fold increase \pm s.e.m, $\mathrm{n}=3$. ${ }^{*} \mathrm{p}<0.05$, $* * *<0.001$ using Student's t-test.

doi:10.1371/journal.pone.0014665.g002

this is also consistent with the literature describing $\operatorname{PPAR} \alpha$ as inhibitor of VEGF signaling through blocking of Akt but not ERK $1 / 2$ activation.

Since PPAR $\alpha$ is known to inhibit NF- $\mathrm{B}$ activation, we monitored NF- $\kappa \mathrm{B}$ activation in NOX1-deficient MLEG in response to VEGF or bFGF stimulation (30 minutes). NOX1deficient MLEC showed reduced nuclear translocation of the NF$\kappa \mathrm{B}$ p65 subunit compared to WT cells in response to VEGF or bFGF as demonstrated by Western blotting on nuclear extracts and immunofluorescence of endothelial cells (Figure $5 \mathrm{~d}$ and Figure S6). Using endothelial cell lines, we then demonstrated that inhibition of NF- $\kappa \mathrm{B}$ translocation depended on PPAR $\alpha$ activation. Indeed, in NOX1-silenced cells PPAR $\alpha$ expression was upregulated (Figure 5a). When these cells were treated with the PPAR $\alpha$ antagonist GW6471 before angiogenic stimulation, deficient nuclear translocation of NF-kB was no longer observed (Figure 5e and Figure S6). Moreover in NOX1 deficient cells, PPAR $\alpha$ and NF- $\kappa \mathrm{B}$ target genes were deregulated (Table 1). For example: Vascular NOX1 deficiency leads to upregulation of the anti-oxidant genes catalase, gluthatione peroxydase- 3 and the antimigratory gene VE-Cadherin, while downregulating the proangiogenic genes MMP2, MMP9, uPAR, VEGF and bFGF.
Incubation of NOX1 silenced cells with the PPAR $\alpha$ antagonist GW6471 blocked this effect, suggesting that regulation of these was dependent on PPAR $\alpha$ activity (Table 1$)$.

\section{Host NOX1 promotes tumor angiogenesis and tumor progression}

The above findings led us to investigate whether NOX1 may contribute to tumor progression by promoting tumor vascularization. To this end, we implanted tumorigenic B16F0 melanoma cells or Lewis Lung Carcinoma (LLC1) cells subcutaneously into WT and NOX1-deficient mice. LLC1 cells expressed high level of NOX1 in contrast to B16F0 cells. We observed reduced tumor vascularization in NOX1-deficient animals with B16F0 melanoma but not with LLC1 tumors (Figure 6a-b).

To assess whether NOX1 may be a valuable target for cancer therapy, we used the inhibitor GKT136901. This inhibitor did not interfere with tumor cell proliferation and apoptosis in vitro but it impinged in their ROS producing activity (Figure S7). One day after LLC1 injection, tumor bearing mice were treated daily by oral administration of GKT136901 at $40 \mathrm{mg} / \mathrm{kg}$. After one week of treatment, the size of tumor in GKT136901-treated mice was $34 \% \pm 5.8$ smaller compared to tumors in vehicle-treated mice 


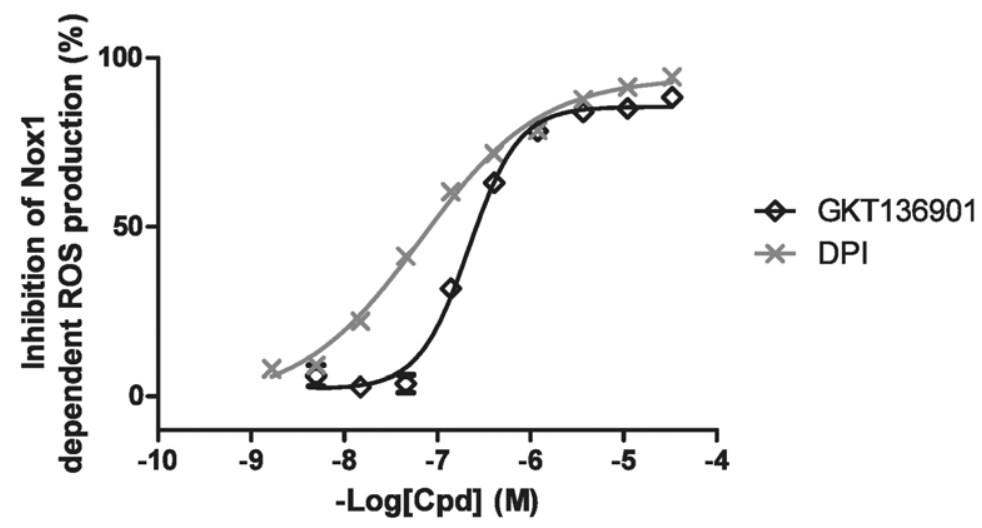

B

\begin{tabular}{|r|r|r|r|r|}
\hline & Ki Nox1 & Ki Nox2 & Ki Nox4 & Ki XXO \\
\hline GKT136901 & $160 \mathrm{nM}$ & $1530 \mathrm{nM}$ & $170 \mathrm{nM}$ & $>100 \mu \mathrm{M}$ \\
\hline DPI & $60 \mathrm{nM}$ & $70 \mathrm{nM}$ & $70 \mathrm{nM}$ & $50 \mathrm{nM}$ \\
\hline
\end{tabular}

Figure 3. Inhibition of NOX1-dependent ROS production by GKT136901. (a) Concentration-response curve of GKT136901 ( $\diamond)$ and DPI (x) on membranes prepared from NOX1 over-expressing cells. Results represent one out of four experiments performed in triplicate. Values are presented as means \pm s.e.m. (b) Affinities of GKT136901 and DPI on NOX1, NOX2, NOX4 and Xanthine Oxidase. GKT136901 is a NADPH-oxidase specific inhibitor, with selectivity on NOX1 and NOX4 over NOX2, whereas DPI inhibits all the NADPH oxidases tested with the same potency. doi:10.1371/journal.pone.0014665.g003

(Figure 6c). This treatment had no toxic effect on mice as illustrated by the Figure S8. Quantification of tumor vasculature by PECAM-1 immunostaining showed $59 \% \pm 9.3$ reduction of vascular area in GKT136901-treated tumors as compared to vehicle treated animals (Figure $6 \mathrm{~d}$ ). In addition, we performed a therapeutic assay by treating animals bearing established tumors (i.e. starting 8 days after tumor implantation) with GKT136901 or the anti-VEGFR2 antibody DG101, as a positive control. Tumor volume was measured daily during treatment. Both treatments delayed tumor progression (35\% \pm 5.7 and $35 \% \pm 9.7$ respectively) and vascularization $(36 \% \pm 16$ and $43 \% \quad \pm 20$ respectively) (Figure 6e, f). From these results, we conclude that NOX1 plays a critical role in promoting tumor angiogenesis and tumor progression.

To further analyze the link between NOX1 and PPAR $\alpha$ in vivo, we injected LLC1 or B16F0 tumor cells in either WT or PPAR $\alpha$ deficient mice and treated these animals with the NOX1 inhibitor GKT136901. Vascularization of these tumors was analyzed by PECAM-1 immunostaining. In WT mice, the inhibitor blocked LLC 1 and $\mathrm{B} 16 \mathrm{~F} 0$ tumor vascularization $(100 \% \pm 24$ vs $65 \% \pm 13$ and $100 \% \pm 15$ vs $64 \% \pm 14)$, whereas it had no effect in PPAR $\alpha$ deficient mice $(100 \% \pm 17$ vs $129 \% \pm 23$ and $100 \% \pm 26$ vs $98 \% \pm$ 24) (Figure 6g,h).

From these observations, we conclude that NOX1 promotes tumor angiogenesis by inhibiting the anti-angiogenic factor PPAR $\alpha$.

\section{Discussion}

Reactive oxygen species are important players in cancer biology [36-38]. At high levels, they induce apoptosis and/or senescence while at homeostatic levels they influence survival and proliferation. In tumor endothelial cells, NOX enzymes contribute to angiogenesis through ROS-dependent mechanisms, and thereby promote tumor growth. In this study, we show that vascular
NOX1, but not NOX2 or NOX4, is an important regulator of angiogenesis, through the modulation of endothelial migration and tube formation. We furthermore identified that NOX1 activity suppresses the anti-inflammatory nuclear hormone receptor PPAR $\alpha$ as a critical mechanism mediating these effects (Figure 7).

Inhibition of NOX1 decreases endothelial cell migration. A link between NOX1, ROS and cell migration has been previously described with non-endothelial cells such as colon carcinoma cell lines [39]. In addition, Schröder et al. reported that blocking NOX1 reduced FGF-stimulated migration of smooth muscle cells through NOX1 dependent ROS activation of JNK, which in turn phosphorylated paxillin [40]. Modulating smooth muscle cell migration may not only be restricted to NOX1, as NOX4 showed similar effects [41]. However, these conflicting data may be due to the different mode of smooth muscle cell activation by bFGF and PDGF, respectively. Based on these data, it is clear that NOX1 and derived ROS products impede the migration of vascular smooth muscle and tumor cells. The role of NOX1 in endothelial cell migration and angiogenesis was previously neglected probably due to the fact that in resting endothelial cells NOX1 is expressed at low levels and is up-regulated only during the angiogenic switch as we show in this study.

Importantly, we do not find evidence for the involvement of the other tested NOX isoforms 2 and 4 in bFGF-induced angiogenesis in vivo. This is in contrast to other reports suggesting an angiogenic role for these NOX isoforms. Angiopoietin-1, VEGF, or thrombin-induced neovascularization in vitro and in vivo have been suggested to be dependent on NOX2 [42-45]. Furthermore, a recent study showed that inhibitors specific for NOX4 and NOX2 blocked hemangioma (i.e. endothelial cell-derived tumor) growth in vivo [33]. Other laboratories found NOX4 responsible for basal endothelial ROS production and cell proliferation [46]. The function of NOX2 and NOX4 in angiogenesis may depend on the type of stimulation and operate by a different mechanism than NOX1, as both enzymes are involved in endothelial cell 
A

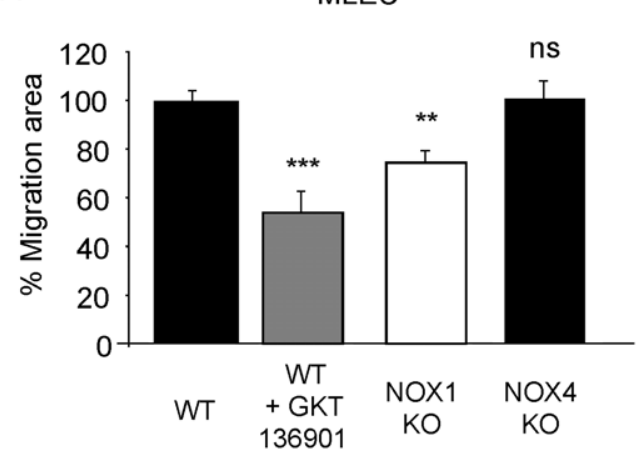

D

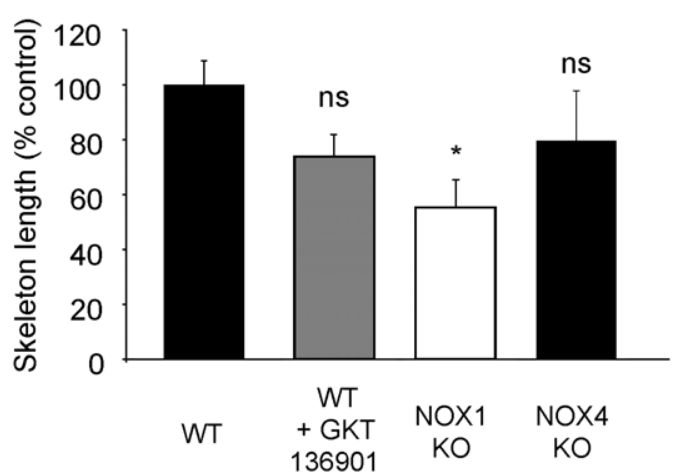

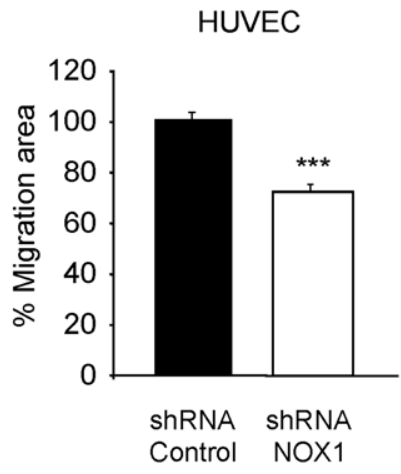

$\mathrm{E}$

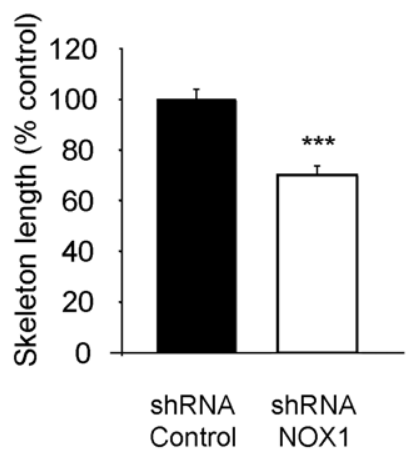

C

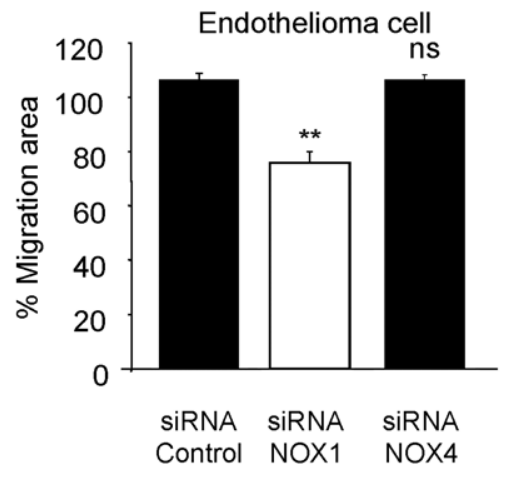

$\mathrm{F}$

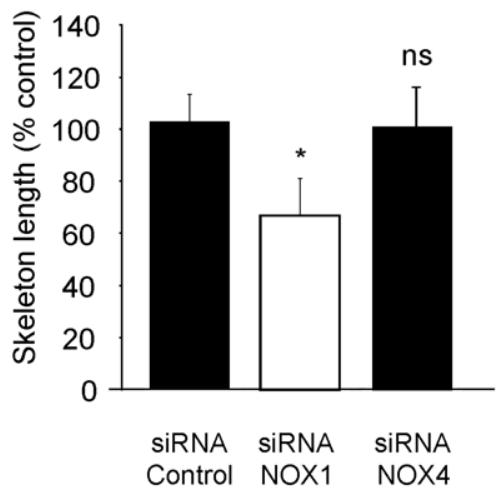

Figure 4. NOX1 inhibition blocks endothelial cell migration and tube-like structure formation. In vitro migration was analyzed by wound-healing assay on mouse primary endothelial cells (a), human primary endothelial cells (b) and endothelioma cell lines (c). Tubular structure formation was measured by 3D culture of mouse primary endothelial cells (d), human primary endothelial cells (e) or endothelioma cell lines ( $f$ ). Results are expressed in \% of control \pm s.e.m, $n=3 .{ }^{*} p<0.05,{ }^{* *} p<0.01,{ }^{* * *}<0.001$ using Student's t-test. GKT136901 was used at $10 \mu M$. doi:10.1371/journal.pone.0014665.g004

proliferation, while NOX1 mediates endothelial cell migration and sprouting but not proliferation.

Our results reveal a remarkable specificity of NOX isoforms. Clearly, endothelial cells express NOX1, NOX2, NOX4, and - at least in humans - also NOX5. Yet, their functions appear to be non-redundant. The specificity of NOX isoforms relies on several elements, including different subcellular localization (NOX4 is predominantly intracellular, while NOX1 rather localizes to caveolae [47]), different activation mechanisms (NOX4 appears constitutively active, while NOX1 and NOX2 are activationdependent, $[10,48])$, and there is also isoform-specific upregulation of NOX mRNA in response to given stimuli. Most likely three elements contribute to the unique role of NOX1 in angiogenesis: i) its localization within caveolae is in proximity of other signaling molecules, ii) to mediate VEGF signaling, it should be an activation inducible enzyme, rather than constitutively active such as NOX4; and iii) as shown in Fig. 2, its mRNA is indeed upregulated in response to VEGF, which adds specificity to the system. Thus, the understanding of which NOX isoforms are relevant for angiogenesis, provided by our study adds new understanding of redox biology. However, the precise identification of the NOX isoform involved in a given pathophysiological process will also be the key for the development of specifically targeted NOX inhibitors [49].

With respect to tumor growth, we observed differences between NOX1-deficient mice and wildtype mice treated with the NOX inhibitor. Indeed, while plug- and tumor-induced angiogenesis was efficiently decreased in the NOX1-deficient mouse and by the NOX inhibitor, the latter was markedly more efficient in decreasing tumor growth. The most likely explanation for this difference is the possibility that NOX enzymes within the tumor cells are contributing to tumor growth and that the NOX inhibitor targets these enzymes. Indeed, there is ample evidence in the literature for a role of NOX enzymes in enhancing growth of tumor cells [50-53]. Moreover, we found that vascularization was substantially diminished in B16 tumors lacking endogenous NOX1 expression, while NOX1-expressing LLC1 tumors were normally vascularized in NOX1 deficient mice. This apparent discrepancy is consistent with the literature, showing that exogenous ROS impacts on endothelial cell proliferation, migration and tube formation [54-56]. Induction of angiogenesis may be due to NOX1 expression by LLC1 tumors, producing high amounts of ROS in the tumor microenvironment and modulating endothelial cell functions. This amount of ROS seems to be sufficient to stimulate endothelial cell proliferation and migration to form new vessels within the tumor. In the GKT136901-treated mice, the tumor cells cannot stimulate ROS mediated angiogenesis as the inhibitor also blocks ROS production by LLCl tumor cells (Figure S6c). Another obvious difference between the NOX1-deficient mice and the NOX inhibitor is the fact that GKT136901 efficiently inhibits NOX4, in addition to NOX1. This point is particularly pertinent because previous studies have implicated NOX4 in mechanisms of angiogenesis. To understand these apparent differences, angiogenic 
A

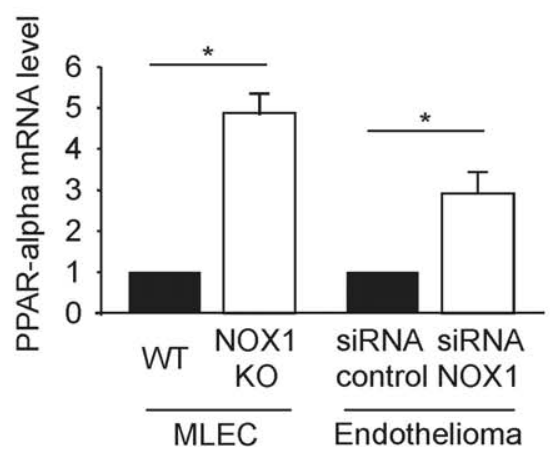

B

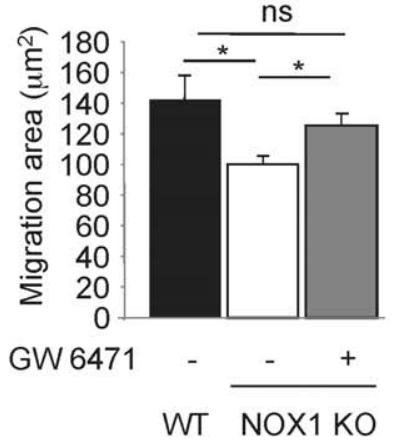

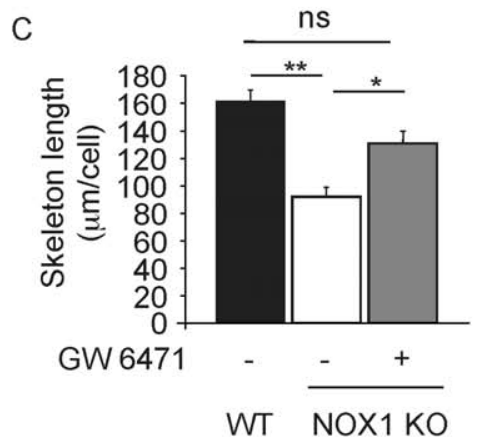

D
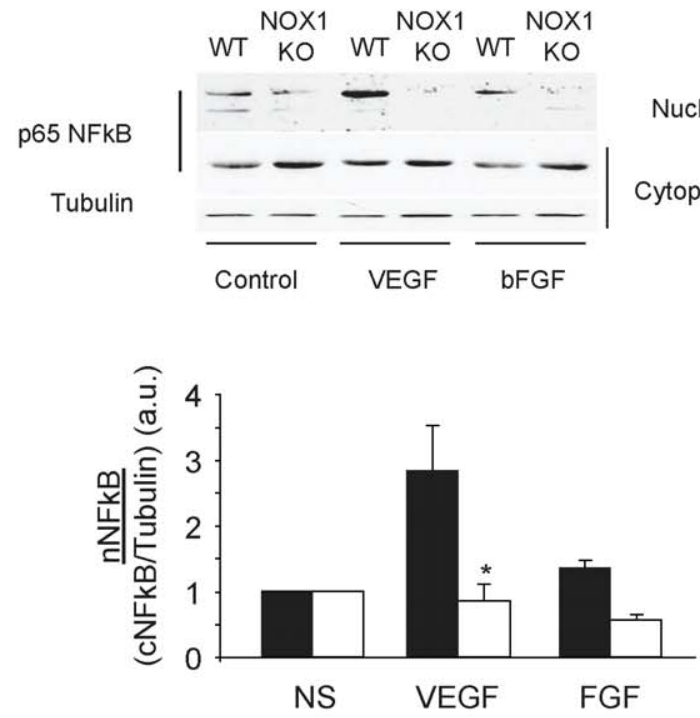

Nucleus

Cytoplasm
E

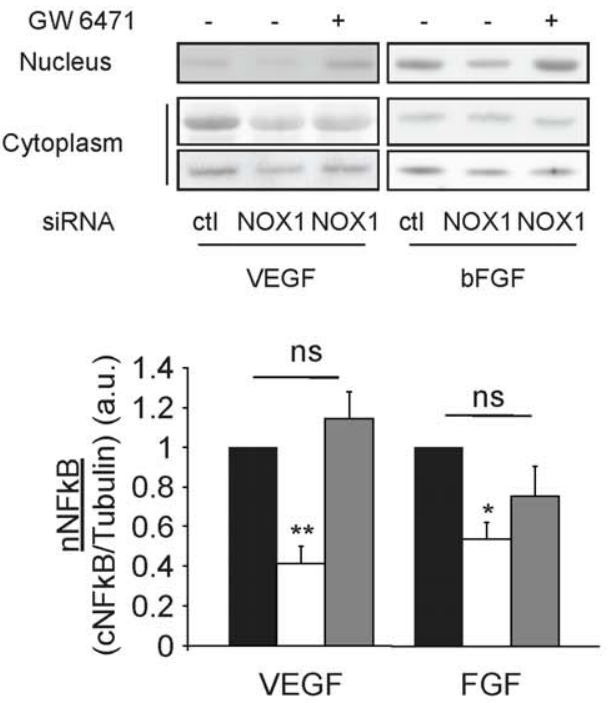

Figure 5. NOX1 negatively regulates PPAR $\alpha$ expression and activity. NOX1 deficiency induces an up-regulation of PPAR $\alpha$ expression and inhibition of pro-angiogenic signaling in endothelial cells. (a). Expression level of PPAR $\boldsymbol{\alpha}$ in MLEC and endothelioma cell lines by quantitative real-time PCR, normalized to the tubulin expression. (b-c) PPAR $\boldsymbol{\alpha}$ antagonist, GW6471 compensated NOX1 deficiency in MLEC. (b). Migration of NOX1-deficient MLEC in presence or absence of PPAR $\boldsymbol{\alpha}$ antagonist $(10 \mu \mathrm{M})$. (c). Tube-like structure formation of NOX1-deficient MLEC in presence or absence of PPAR $\boldsymbol{\alpha}$ antagonist $(10 \mu \mathrm{M})$. VEGF and b-FGF induced-NFKB nuclear translocation is inhibited in absence of NOX1 and is dependent on PPAR $\boldsymbol{\alpha}$ activity. (d). Western blot analysis of p65 NFKB in nuclear and cytoplasmic fractions of WT and NOX1-deficient cells stimulated 30 min with VEGF and bFGF $(20 \mathrm{ng} / \mathrm{ml})$. (e). Western blot analysis of p65 NFkB in nuclear and cytoplasmic fractions of NOX1-silenced cells treated or not with $10 \mu M$ of GW6471 before stimulation with VEGF and bFGF. The graphs show the abundance of nuclear p65 NF-kB relative to cytoplasmic p65 NF- $\mathrm{kB} \pm$ s.e.m as determined by densitometry. $n=3$. ${ }^{*} p<0.05,{ }^{* *} p<0.01$ (Student's t-test).

doi:10.1371/journal.pone.0014665.g005

Table 1. Expression of genes regulated by NOX1 deficiency.

\begin{tabular}{llll}
\hline & & & \\
\hline & LMEC NOX1 KO & tEnd siRNA NOX1 & tEnd siRNA NOX1 + GW 6471 \\
\hline Catalase & $1.52 \pm 0.29$ & $1.52 \pm 0.19$ & $0.92 \pm 0.012$ \\
GPX3 & $1.47 \pm 0.08$ & $1.49 \pm 0.13$ & $0.70 \pm 0.01$ \\
VE-cadherin & $2.29 \pm 0.07$ & $1.54 \pm 0.28$ & $0.9 \pm 0.2$ \\
MMP-2 & $0.43 \pm 0.24$ & $0.97 \pm 0.10$ & $2.13 \pm 0.24$ \\
MMP-9 & $0.29 \pm 0.13$ & $0.89 \pm 0.13$ & $0.47 \pm 0.07$ \\
UPAR & $0.41 \pm 0.12$ & $0.76 \pm 0.19$ & $1.34 \pm 0.6$ \\
VEGF & $0.31 \pm 0.05$ & $2.04 \pm 0.29$ & $0.68 \pm 0.04$ \\
bFGF & $0.71 \pm 0.21$ & $0.81 \pm 0.13$ & $0.64 \pm 0.25$ \\
VCAM-1 & $0.84 \pm 0.01$ & $0.76 \pm 0.04$ & $0.57 \pm 0.18$ \\
\hline
\end{tabular}

Level of expression of target genes in NOX1 deficient primary endothelial cells (MLEC), or silenced cells endothelial cell lines compared to control cells, analyzed by quantitative real-time PCR. Results are expressed in fold increase or decrease \pm s.e.m. $n=3$.

doi:10.1371/journal.pone.0014665.t001 


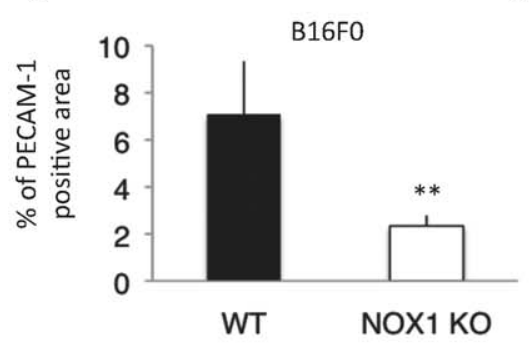

C

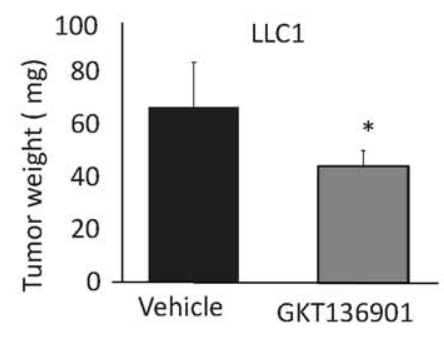

$E$

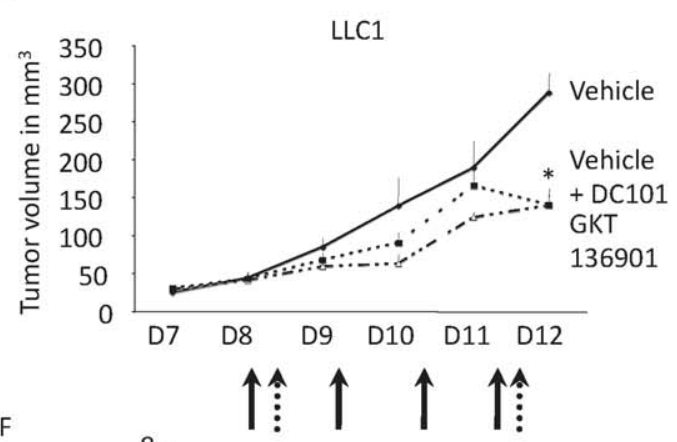

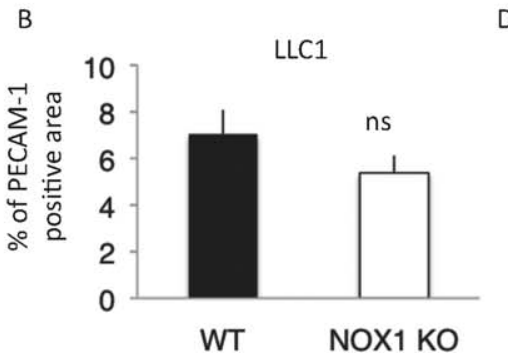

G

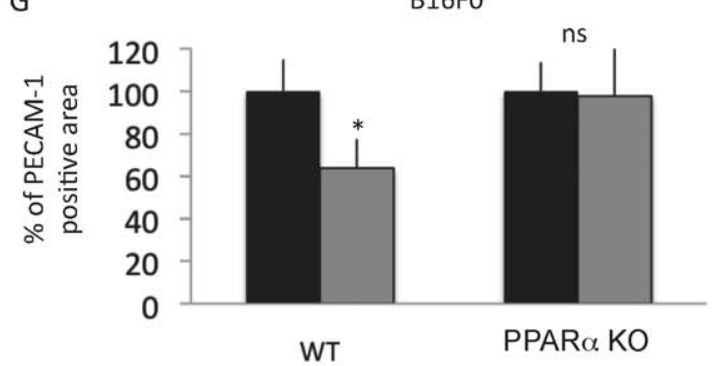

LLC1
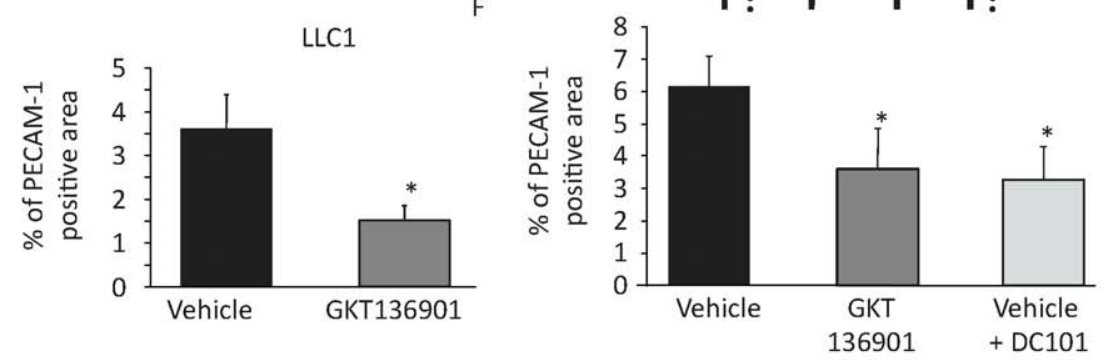

$\mathrm{H}$

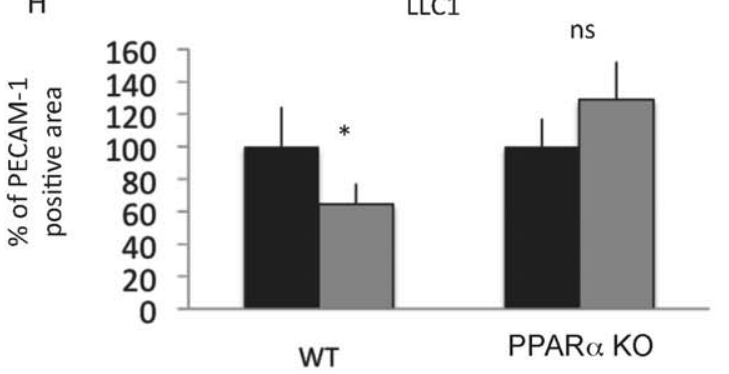

Figure 6. NOX1 inhibition reduces tumor growth and angiogenesis. B16F0 (a) or LLC1 (b) tumor cells were injected subcutaneously into WT or NOX1 KO mice. Tumors were allowed to develop for 10 days and the density of tumor vasculature was identified using PECAM-1 staining by measuring the positive (vascular) and total (tumor) area \pm s.e.m expressed as percentage. $n=8$; WT mice injected with LLC1 tumor cells were then treated with the NOX inhibitor GKT136901 at $40 \mathrm{mg} / \mathrm{kg} /$ day by oral administration for 8 days; (c). Graph represents tumor weight in $\mathrm{mg} \pm$ s.e.m $\mathrm{n}=8$ per group. (d). Tumor vessel density in tumors from the experiment in (c). Graph shows tumor vascularization expressed in percentage of PECAM-1 positive area \pm s.e.m.; (e). Changes in tumor volume in $\mathrm{mm}^{3}$ after therapeutic treatment starting 8 days post tumor cell injection with GKT136901 (black arrows) or anti-VEGFR2 (DC101) (pointed arrows). Tumor volume is measured using a caliper and the formula $V=4 / 3 \pi(L / 2 * 1 / 2 * w / 2)$. $n=8 ;(f)$. Blood vessel density in tumors from the experiment in (e). at day 12. Graph shows tumor vascularization expressed in percentage of PECAM-1 positive area \pm s.e.m. WT or PPAR $\alpha$ KO mice injected with B16FO (g) or LLC1 (h) were then treated with the NOX inhibitor GKT136901 at $40 \mathrm{mg} / \mathrm{kg} / \mathrm{day}$ by oral administration for 8 days. Graph shows tumor vascularization expressed in percentage of PECAM-1 positive area \pm s.e.m. $n=6 .{ }^{*} p<0.05,{ }^{* *} p<0.01$ (Student's t-test).

doi:10.1371/journal.pone.0014665.g006

responses should be subdivided in a proximal response of the hypoxic tissue (HIFl $\alpha$ activation and VEGF production) and a distal response of the endothelial cells (VEGF-induced neovascularization). Our results (Fig. 1) clearly demonstrate that NOX4 is not involved in the distal response of endothelial cells. However, our results do not argue against a role of NOX4 in the proximal response of hypoxic tissues. Indeed, based on the literature [57,58], we think that such a role of NOX4 is likely.

Under homeostatic conditions, ROS levels are balanced by scavenger and antioxidant enzymes. As in certain pathologies this balance becomes deregulated and much effort has been put into development of inhibitors of ROS production [59]. Since most ROS-related diseases are mediated by one NOX isoform only, novel inhibitors, which are isoform specific, will be invaluable. The novel GenKyoTex inhibitor, GKT136901, has been developed for this purpose and appears to be specific for NOX1 and NOX4 with similar affinities. In vitro, this inhibitor blocked ROS production induced by proangiogenic factors and inhibited endothelial cell migration. More importantly, the level of this inhibition was comparable to that observed in NOX1-deficient cells. With NOX4-deficient endothelial cells however, we observed no reduced migration. From these data we conclude that endothelial cell migration is NOX1 dependent and NOX4 independent. Furthermore, the potential for GKT136901 to be used as a NOX1/4 specific inhibitor in prevention of tumor angiogenesis is also demonstrated.

We observed an increase of PPAR $\alpha$ expression when NOX1 was not expressed; suggesting that NOX1 activity constitutively represses PPAR $\alpha$ expression. As previously mentioned, in the absence of NOX1 expression, endothelial cells were less able to migrate and to form tubular structures, we showed that this effect was reversed using an antagonist of PPAR $\alpha$. Moreover, in NOX1deficient endothelial cells, NFאB was not activated after VEGF or bFGF stimulation. This effect was reversed by treatment with a $\operatorname{PPAR} \alpha$ antagonist. In addition, anti-oxidants and anti-migratory genes were up-regulated and pro-angiogenic genes down-regulat- 
Tumor cells and leukocytes

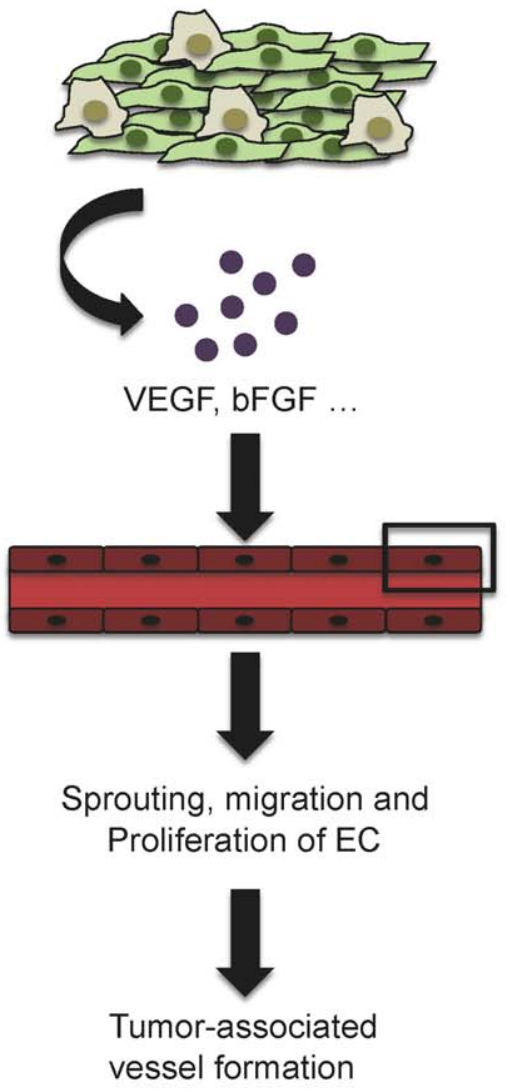

A

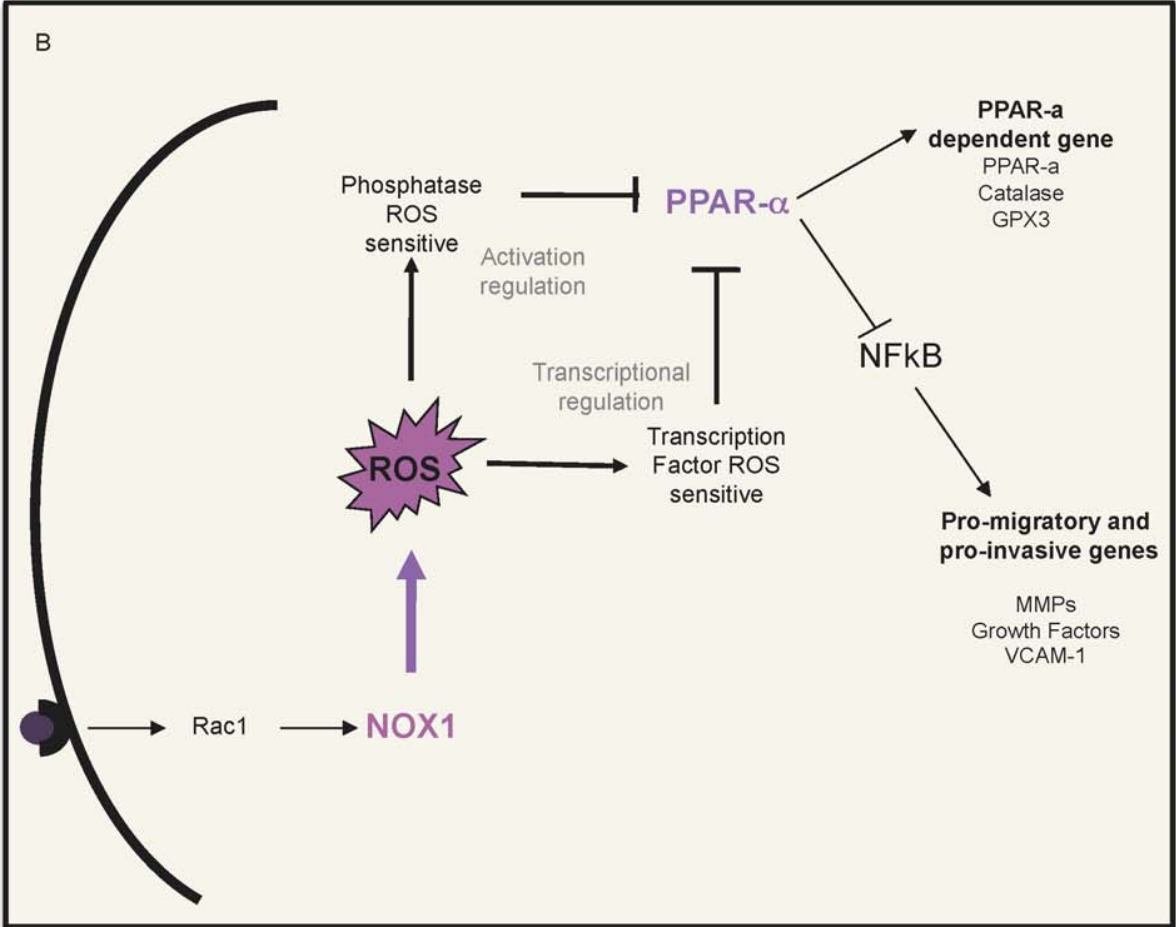

Figure 7. Schematic representation of the role of NOX1 in tumor angiogenesis. (a) Tumor cells and tumor-infiltrating leukocytes during tumor development produce proangiogenic factors such as VEGF and bFGF. These factors activate the preexisting vessels to form neovessels by sprouting, migration and proliferation. (b) Endothelial cells receive the angiogenic stimulus by fixation of the angiogenic factor to the surface receptor. This interaction initiates a signaling cascade, which leads to NOX1 activation through Rac1. NOX1 dependent ROS inhibits the nuclear hormone receptor PPAR $\boldsymbol{\alpha}$ by post-translational modification and transcriptional regulation. This inhibition leads to NF- $\mathrm{\kappa B}$ activation and transcription of angiogenic factors such as MMPs, growth factors or promigratory molecules.

doi:10.1371/journal.pone.0014665.g007

ed by NOX-1 deficiency. These differences in gene expression depended on PPAR $\alpha$ transactivation and they explain the reduced migratory phenotype and tube formation of NOX1 deficient endothelial cells. PPAR $\alpha$ activity, which itself controls PPAR $\alpha$ expression, could be directly regulated by the catalytic activity of NOX1. Indeed, PPAR $\alpha$ activity is regulated by several posttranscriptional modifications such as phosphorylation or SUMOylation [60,61], which may be ROS sensitive [62]. It has been previously shown that ROS inactivates phosphatases [63,64] and activates SUMOylation [62,65]. Thus, upregulation of PPAR $\alpha$ expression and activity in NOX1-deficient cells blocks angiogenic signaling needed for endothelial cell migration, sprouting and angiogenesis.

Currently, the anti-VEGF antibody bevacizumab (Avastin), and several small molecular VEGFR tyrosine kinase inhibitors, are used as anti-angiogenic drugs to treat patients with advanced cancers $[66,67]$. Anti-angiogenic therapy targets non-transformed endothelial cells and results in the reduced delivery of nutrients and oxygen to tumor cells. However, concomitant chemotherapy is needed in order to obtain a survival advantage. Emerging evidence indicates that tumors treated with anti-angiogenic therapy elicit compensatory reactions by inducing the production of alternative angiogenic factors. Thus, the question arises as to whether anti-NOX therapy could potentially be a therapeutic approach complementary to anti-VEGF treatment. Indeed, expression of NOX molecules are induced in vascular endothelium and in tumor cells during the angiogenic switch and inhibition of NOX1 in both the host and the tumor cells using the potent NOX1 inhibitor GKT136901, results in reduced tumor angiogenesis and tumor growth. Moreover NOX1 seems to form a common angiogenic pathway, at least for signaling induced by VEGF and FGF. As a result, NOX1 inhibition could bypass the potential compensatory mechanisms activated by anti-VEGF therapy.

In conclusion, we have identified NOX1 as a novel mediator of angiogenesis and as a candidate therapeutic target for antiangiogenic therapies in cancer.

\section{Materials and Methods}

Mice

NOX1, NOX2, NOX1/2, NOX4 deficient mice were inbred on the C57BL/6J background for more than 6 generations. The PPAR $\alpha$ null animals were originally described in [68]. All animal procedures were performed in accordance with the Institutional Ethical Committee of Animal Care in Geneva and Cantonal 
Veterinary Office. The Institutional Ethical Committee of Animal Care in Geneva and Cantonal Veterinary Office specifically approved this study through experimentation IDs: 31.1.10053456-0, 1005-3325-1, 1005-3329-2.

\section{Cells and reagents}

Endothelial cell line (thymus derived endothelioma [69]) was cultured in Dulbecco Modified Eagle medium supplemented with 10\% FCS, $100 \mathrm{U} / \mathrm{ml}$ Penicillin/Streptomycin, $100 \mathrm{U} / \mathrm{ml}$ Glutamine. Primary lung endothelial cells were cultured in DMEM/ HAM F-12 medium supplemented with $20 \%$ of FCS, $100 \mathrm{U} / \mathrm{ml}$ Penicillin/Streptomycin, $100 \mathrm{U} / \mathrm{ml}$ Glutamine, $100 \mu \mathrm{g} / \mathrm{ml} \mathrm{Hep-}$ arin (Sigma-Aldrich), $10 \mu \mathrm{g} / \mathrm{ml}$ Endothelial cell growth supplement (Upstate). MLEG were used from passage 4 to 6 . Human umbilical vein endothelial cells (HUVEC) were isolated in the laboratory, cultured in Bullet kit (Lonza) and used from passage 4 to 6. Gelatin, Fibronectin, Fibrinogen, and Aprotinin were obtained from Sigma Aldrich. Growth factor reduced Matrigel was from Becton Dickinson. Murine and human bFGF, human and murine VEGF were from Peprotech. Antibodies against phospho-p42/44 MAPKinase, total MAPKinase, phosphoThr308 Akt and total Akt were purchased from Cell Signaling Technology. Antibody against NF-kB p65 was purchased from SantaCruz Biotechnology and anti-Actin antibody was kindly provided by Dr Christine Chaponnier. DC101 hydridoma was purchased from ATCG (Manassas, VA) and DC101 antibody was expressed and purified at the protein expression facility at EPFL, Lausanne.

\section{In vivo angiogenesis assay}

7 to 10 week old females were injected subcutaneously with $400 \mathrm{ml}$ of growth factor reduced Matrigel supplemented with $500 \mathrm{ng} / \mathrm{ml}$ of bFGF. One week later, mice were scanned using Micro-CT (Skyscan-1076). Mice were scanned before and after retro-orbital injection of $400 \mathrm{ml}$ iodinated liposomes (BR22, BracoResearch, Plan-les-Ouates) to visualize the vessel density in the plug as described previously [70,71].

\section{MLEC isolation}

Murine lung endothelial cells were isolated as described previously [27]. Briefly, whole mouse lungs were digested in collagenase type I $0.1 \%$ (Gibco). Digest lung were plated on gelatin/collagen/fibronectin-coated flask in DMEM/HAM F-12 medium supplemented with $20 \%$ of FCS, $100 \mathrm{U} / \mathrm{ml}$ Penicillin/ Streptomycin, $100 \mathrm{U} / \mathrm{ml}$ Glutamine, $100 \mu \mathrm{g} / \mathrm{ml}$ Heparin (SigmaAldrich), $10 \mu \mathrm{g} / \mathrm{ml}$ Endothelial cell growth supplement (Upstate). The following day, macrophages were depleted from the culture by negative selection using a rat anti-mouse FcgRII/III antibody coupled to anti-rat coated magnetic beads (Dynal). Cells were then positively selected twice using the endothelial marker, PECAM-1 (Figure S3).

\section{Quantitative RT-PCR}

Total RNA from treated cells was extracted using RNeasy minikit (Qiagen). Total RNA was reverse-transcribed with the Superscript III first strand RT-PCR kit (Invitrogen). Quantitative real-time PCR was performed using SybrGreen master mix (Applied Biosystems) on Step one plus Real-time PCR machine (Applied Biosystems). Primer sequences are listed in the Materials and Methods S1.

\section{Detection of superoxide}

Endothelial cells were seeded on glass slides and stained with dihydroethidium (DHE). Images were captured with an inverted microscope and analyzed with Metafluor imaging software (MDS Analytical Technologies). Quantification was performed by measuring the fluorescence intensity of over minimum 50 endothelial cells per slide.

\section{NOX inhibition in cell free assays and pharmacological profile of GKT136901}

Membranes from NOX2 expressing PMN cells or from cells overexpressing NOX1 or NOX4 were prepared as previously described [29]. After resuspension in sonication buffer $(11 \%$ sucrose, $120 \mathrm{mM} \mathrm{NaCl}, 1 \mathrm{mM}$ EGTA in PBS, pH 7.4 for NOX4expressing cells) or in relax buffer $(10 \mathrm{mM}$ Pipes, $3 \mathrm{mM} \mathrm{NaCl}$, $3.5 \mathrm{mM} \mathrm{MgCl2}, 0.1 \mathrm{M} \mathrm{KCl}, \mathrm{pH} 7.4$ ), cells were broken by sonication and centrifuged (200 g, $10 \mathrm{~min}$ ). The supernatant was loaded onto a $17 / 40 \%(\mathrm{w} / \mathrm{v})$ discontinuous sucrose gradient and centrifuged $(150,000 \mathrm{~g}$ for $30 \mathrm{~min})$. Membrane fractions were collected and stored at $-80^{\circ} \mathrm{C}$. ROS production measurements of membranes expressing different NOX subunits was determined as previously described [30] using the Amplex Red method (Invitrogen). Membranes prepared from non-transfected cells did not show NADPH-induced ROS production (data not shown).

\section{Gene silencing}

For mouse cells, siRNAs were nucleofected using the Amaxa technology (Lonza). Gene silencing was assessed 48 hours after nucleofection by quantitative RT-PCR. For HUVEC, shRNA vectors (SABiosciences) were nucleofected using Amaxa. Gene silencing was assessed 48 hours after nucleofection by quantitative RT-PCR.

\section{Wound healing assay}

Wound healing assay was performed as described previously [72]. Briefly, endothelial cells were plated in Matrigel (Becton Dickinson) precoated 96 wells plates. One day after plating the cell monolayer was scratched to make a regular wound. Cells were allowed to migrate overnight. Migration area was then measured and calculated using the Metamorph program (MDS Analytical Technologies).

\section{Endothelial cell sprouting assay}

Sprouting assay was performed as described previously [72]. Briefly, endothelial cells were plated in 96 well plates at 8,000 cells per well in a $3 \mathrm{D}$ fibrin gel. Above the gel, 10\% FCS containing DMEM was complemented with $200 \mathrm{KIU} / \mathrm{ml}$ of Aprotinin (Sigma). Length of branches was evaluated using the Metamorph program. Results are expressed in mm of skeleton length/number of cells.

\section{Nuclear and cytoplasmic extraction}

After stimulation, nuclear and cytoplasmic proteins of endothelial cells were extracted according to Tauzin et al. [73]. Briefly, cells were incubated in TKM buffer (50 mM Tris-HCl pH 7.4, $25 \mathrm{mM} \mathrm{KCl}, 5 \mathrm{mM} \mathrm{MgCl}_{2}$ and $1 \mathrm{mM}$ EGTA) containing $1 \%$ Triton and protease inhibitor cocktail CLAP $[10 \mu \mathrm{g} / \mathrm{ml}$ chymostatin, leupeptin, antipain and pepstatin A (Sigma) for 30 minutes on ice, sonicated for 2 minutes and centrifuged at $5000 \mathrm{~g}$ for 30 minutes. The pellet and the supernatant were separated and solubilized in sample buffer.

\section{Western blotting}

Cells were stimulated for the indicated time and then lysed in TNT buffer (50 mM Tris, $150 \mathrm{mM} \mathrm{NaCl,} \mathrm{0.5 \%} \mathrm{Triton} \mathrm{X-100)} \mathrm{comple-}$ mented with protease inhibitor cocktail CLAP and phosphatase 
inhibitor cocktail [ $25 \mathrm{mM} \mathrm{NaF}, 20 \mathrm{mM}$ b-Glycerophosphate, $5 \mathrm{mM}$ HEPES, $2.5 \mathrm{mM}$ EDTA, $0.5 \mathrm{mM}$ Orthovanadate]. Membranes were blocked in PBS containing $0.5 \%$ BSA and hybridized with different antibodies. Blots were revealed with peroxidase coupled secondary reagent (Jackson Immunoresearch) followed by ECL and quantified by densitometry using Image $\mathrm{J}$ software.

\section{Tumor growth assay}

5. $10^{5}$ of LLC1 or B16F0 were injected subcutaneously on the back of mice. Mice were treated with NOX inhibitor, GKT136901 or vehicle (Carboxymethyl-cellulose, GMC) at $40 \mathrm{mg} / \mathrm{kg}$ everyday per os or i.p with anti-VEGFR 2 antibody (DC101) at $0.8 \mathrm{mg}$ every 2 days. When the control tumor reached approximately $1 \mathrm{~cm}$ in length, mice were sacrificed and the tumor excised, weighed and frozen. Frozen sections of tumors were stained with anti-PECAM-1 antibody (rat monoclonal, [74]).

\section{Statistical analysis}

All statistical analysis was performed using Anova on multiple variable analyses and Student's t-test on paired analyses. $*(\mathrm{p}=0,05), * *(\mathrm{p}=0,01), * * *(\mathrm{p}=0,001)$.

\section{Supporting Information}

Table S1 Inhibitory effect of the inhibitor GKT 136901 on ROS producing enzymes, redox-sensitive enzymes and others proteins. Found at: doi:10.1371/journal.pone.0014665.s001 (0.03 MB DOC)

Figure S1 MLEC isolation from WT and NOX deficient mice. a. Flow cytometry analysis of endothelial surface molecules on isolated MLEC. PECAM-1, VE-Cadherin, ICAM-2 and Meca-32 expression level in MLEC. b. PECAM-1 immunofluorescence staining of WT, NOX1 KO and NOX4 KO MLEC. Nuclei in blue (DAPI), and PECAM-1 in purple (Cy5). Images were acquired with a 40x/1.3 numeric aperture lens and analyzed using LSM510 Meta microscope (Carl Zeiss).

Found at: doi:10.1371/journal.pone.0014665.s002 (6.76 MB TIF)

Figure S2 Inhibition of NOX-dependent ROS production by GKT136901 and DPI. a. Concentration-response curves of GKT136901 on NOX1 (x), NOX2 $\mathbf{\Delta})$, NOX4 $(\diamond)$ and Xanthine Oxidase $(\mathrm{XO})(\square)$. b. Concentration-response curve of DPI on NOX1 $(\mathrm{x}), \operatorname{NOX} 2(\boldsymbol{\Delta}), \operatorname{NOX} 4(\diamond)$ and Xanthine Oxidase $(\mathrm{XO})(\square)$ Results are from one experiment performed in triplicate, representative of four performed. Values are presented as means \pm s.e.m. Found at: doi:10.1371/journal.pone.0014665.s003 (2.02 MB TIF)

Figure S3 NOX dependant ROS blocking agents efficiently block endothelial cell migration and branching capacities. a. Migration of endothelial cells was analyzed by a wound-healing assay in presence of different inhibitors that block NADPH dependant ROS production. b. Tubular structure formation was measured by $3 \mathrm{D}$ culture using the mouse endothelial cell line in presence of different inhibitors that block NADPH dependant ROS production. Results are expressed in $\%$ of control \pm s.e.m, $\mathrm{n}=3$.

Found at: doi:10.1371/journal.pone.0014665.s004 (5.89 MB TIF)

Figure S4 NOX1 over-expression enhances endothelial cell migration and tube-like structure formation. a. In vitro migration was analyzed by wound-healing assay using endothelioma cell lines transfected with NOX1 expressing vector. b. Tubular structure formation was measured by $3 \mathrm{D}$ culture of endothelioma cell lines transfected with NOX1 expressing vector. Results are expressed in $\%$ of control \pm s.e.m. ${ }^{*} \mathrm{p}<0.05$ using Student's t-test. Found at: doi:10.1371/journal.pone.0014665.s005 (5.88 MB TIF)
Figure S5 AKT but ERK $1 / 2$ activation is affected by NOX1 deficiency. NOX1-deficient MLEC does not activate Akt after bFGF stimulation but present no difference in ERK1/2 activation. a. Western blot analysis of Akt phosphorylation in WT and NOX1deficient MLEC after $10 \mathrm{~min}$ stimulation with $20 \mathrm{ng} / \mathrm{ml}$ of bFGF. The graph shows the abundance of phosphorylated Akt relative to total Akt \pm s.e.m as determined by densitometry. $n=3$. b. Western blot analysis of ERK1/2 phosphorylation in WT and NOX1deficient MLEG stimulated for $10 \mathrm{~min}$ with $20 \mathrm{ng} / \mathrm{ml}$ of bFGF. The graph shows the abundance of phosphorylated ERK1/2 relative to total ERK1/2 \pm s.e.m as determined by densitometry. $n=3$.

Found at: doi:10.1371/journal.pone.0014665.s006 (6.13 MB TIF)

Figure S6 NF- $\kappa \mathrm{B}$ nuclear translocation is inhibited in the absence of NOX1 and dependent on PPAR $\alpha$ activation. VEGF or b-FGF stimulation of endothelial cells induced p65 NF- $\kappa \mathrm{B}$ translocation into the nucleus. This nuclear translocation is not observed in NOX1-deficient cells but restored by PPAR $\alpha$ antagonist treatment (GW6471). Immunofluorescence, anti-p65 NF- $\kappa \mathrm{B}$ of MLEG (a) and endothelioma cell lines (b) stimulated with VEGF or bFGF in presence or absence of GW6471 $(10 \mathrm{mM})$. NF-кB in green (Alexa 488), nuclei in blue (DAPI). Scale bar represent $20 \mathrm{~mm}$. Images were acquired with a 40x/1.3 numeric aperture and analyzed using LSM510 confocal microscope (Carl Zeiss).

Found at: doi:10.1371/journal.pone.0014665.s007 (7.09 MB TIF)

Figure S7 Effect of GKT 136901 on tumor cells. a. LLC1 and $\mathrm{B} 16 \mathrm{~F} 0$ cell proliferation was measured by EdU incorporation and propidium iodide staining of DNA content, $24 \mathrm{~h}$ after incubation with $10 \mu \mathrm{M}$ of GKT136901. b. LLC1 apoptosis was measured by AnnexinV/PI staining after $24 \mathrm{~h}$ of incubation with $10 \mu \mathrm{M}$ of GKT136901. c. ROS levels produced by LLG1 are inhibited by GKT136901. ROS production was quantified by DHE substrate $1 \mathrm{~h}$ after incubation with $10 \mu \mathrm{M}$ of the inhibitor. *** $\mathrm{p}<0.001$ (student t-test).

Found at: doi:10.1371/journal.pone.0014665.s008 (6.11 MB TIF)

Figure S8 Non toxic effect GKT 136901 on mice organs. Heart (a), Kidney (b), Liver (c) and Lung (d) of mice treated orally with vehicle or with vehicle plus GKT136901 inhibitor at $40 \mathrm{mg} / \mathrm{kg}$ per day during 8 days, stained by Hematoxilin/Eosin. Scale bars represent $100 \mu \mathrm{m}$ on the full picture and $20 \mu \mathrm{m}$ on the zoom. Images were acquired with a 20x/0.8 numeric aperture and analyzed using Mirax (Carl Zeiss).

Found at: doi:10.1371/journal.pone.0014665.s009 (8.38 MB TIF)

Materials and Methods S1 Real-time PCR primer sequence list.

Found at: doi:10.1371/journal.pone.0014665.s010 (0.05 MB DOC)

\section{Acknowledgments}

We would like to thank C. Chaponnier (Centre medical Universitaire, Geneva) for the gift of the anti-Actin antibody; N. Deblon (Centre medical Universitaire, Geneva) for advice concerning PPARa; N. Imaizumi (CePO and University of Lausanne, Lausanne) for her assistance in Matrigel plug assay; B. Lee (Centre medical Universitaire, Geneva) for his assistance in the manuscript editing.

\section{Author Contributions}

Conceived and designed the experiments: SGU KHK BI. Performed the experiments: SGU SJ CD SC OB CS FH PP. Analyzed the data: SGU. Contributed reagents/materials/analysis tools: CD SC OB CS FH PP XM LM JA CR KHK. Wrote the paper: SGU KHK BI. 


\section{References}

1. Folkman J (2006) Angiogenesis. Annu Rev Med 57: 1-18.

2. Kerbel RS (2008) Tumor angiogenesis. N Engl J Med 358: 2039-2049.

3. Naumov GN, Akslen LA, Folkman J (2006) Role of angiogenesis in human tumor dormancy: animal models of the angiogenic switch. Cell Cycle 5: 1779-1787.

4. Naumov GN, Bender E, Zurakowski D, Kang SY, Sampson D, et al. (2006) A model of human tumor dormancy: an angiogenic switch from the nonangiogenic phenotype. J Natl Cancer Inst 98: 316-325.

5. Adams RH, Alitalo K (2007) Molecular regulation of angiogenesis and lymphangiogenesis. Nat Rev Mol Cell Biol 8: 464-478.

6. Ferrara N, Kerbel RS (2005) Angiogenesis as a therapeutic target. Nature 438: 967-974.

7. Bedard K, Krause KH (2007) The NOX family of ROS-generating NADPH oxidases: physiology and pathophysiology. Physiol Rev 87: 245-313.

8. Suh YA, Arnold RS, Lassegue B, Shi J, Xu X, et al. (1999) Cell transformation by the superoxide-generating oxidase Moxl. Nature 401: 79-82.

9. Banfi B, Maturana A, Jaconi S, Arnaudeau S, Laforge T, et al. (2000) A mammalian $\mathrm{H}+$ channel generated through alternative splicing of the NADPH oxidase homolog NOH-1. Science 287: 138-142.

10. Banfi B, Clark RA, Steger K, Krause KH (2003) Two novel proteins activate superoxide generation by the NADPH oxidase NOX1. J Biol Chem 278: 3510-3513.

11. Carnesecchi S, Deffert C, Pagano A, Garrido-Urbani S, Metrailler-Ruchonnet I, et al. (2009) NOX1 Plays a Crucial Role in Hyperoxia-Induced Acute Lung Injury in Mice. Am J Respir Crit Care Med.

12. Manea A, Raicu M, Simionescu M (2005) Expression of functionally phagocytetype $\mathrm{NAD}(\mathrm{P}) \mathrm{H}$ oxidase in pericytes: effect of angiotensin II and high glucose. Biol Cell 97: 723-734.

13. Lee NK, Choi YG, BaikJY, Han SY, Jeong DW, et al. (2005) A crucial role for reactive oxygen species in RANKL-induced osteoclast differentiation. Blood 106: 852-859.

14. Lassegue B, Sorescu D, Szocs K, Yin Q Akers M, et al. (2001) Novel gp91(phox) homologues in vascular smooth muscle cells: noxl mediates angiotensin IIinduced superoxide formation and redox-sensitive signaling pathways. Circ Res 88: 888-894.

15. Ago T, Kitazono T, Kuroda J, Kumai Y, Kamouchi M, et al. (2005) NAD(P)H oxidases in rat basilar arterial endothelial cells. Stroke 36: 1040-1046.

16. Kobayashi S, Nojima Y, Shibuya M, Maru Y (2004) Nox1 regulates apoptosis and potentially stimulates branching morphogenesis in sinusoidal endothelial cells. Exp Cell Res 300: 455-462.

17. Fukuyama M, Rokutan K, Sano T, Miyake H, Shimada M, et al. (2005) Overexpression of a novel superoxide-producing enzyme, NADPH oxidase 1, in adenoma and well differentiated adenocarcinoma of the human colon. Cancer Lett 221: 97-104.

18. Szanto I, Rubbia-Brandt L, Kiss P, Steger K, Banfi B, et al. (2005) Expression of NOX1, a superoxide-generating NADPH oxidase, in colon cancer and inflammatory bowel disease. J Pathol 207: 164-176.

19. Laurent E, McCoy JW 3rd, Macina RA, Liu W, Cheng G, et al. (2008) Nox1 is over-expressed in human colon cancers and correlates with activating mutations in K-Ras. Int J Cancer 123: 100-107.

20. Arbiser JL, Petros J, Klafter R, Govindajaran B, McLaughlin ER, et al. (2002) Reactive oxygen generated by Noxl triggers the angiogenic switch. Proc Natl Acad Sci U S A 99: 715-720.

21. Delerive P, De Bosscher K, Besnard S, Vanden Berghe W, Peters JM, et al. (1999) Peroxisome proliferator-activated receptor alpha negatively regulates the vascular inflammatory gene response by negative cross-talk with transcription factors NF-kappaB and AP-1. J Biol Chem 274: 32048-32054.

22. Delerive P, Gervois P, Fruchart JC, Staels B (2000) Induction of IkappaBalpha expression as a mechanism contributing to the anti-inflammatory activities of peroxisome proliferator-activated receptor-alpha activators. J Biol Chem 275: 36703-36707.

23. Panigrahy D, Kaipainen A, Huang S, Butterfield CE, Barnes CM, et al. (2008) PPARalpha agonist fenofibrate suppresses tumor growth through direct and indirect angiogenesis inhibition. Proc Natl Acad Sci U S A 105: 985-990.

24. Blann AD, Belgore FM, Constans J, Conri C, Lip GY (2001) Plasma vascular endothelial growth factor and its receptor Flt-1 in patients with hyperlipidemia and atherosclerosis and the effects of fluvastatin or fenofibrate. Am J Cardiol 87: 1160-1163.

25. Pozzi A, Ibanez MR, Gatica AE, Yang S, Wei S, et al. (2007) Peroxisomal proliferator-activated receptor-alpha-dependent inhibition of endothelial cell proliferation and tumorigenesis. J Biol Chem 282: 17685-17695

26. Marx N, Sukhova GK, Collins T, Libby P, Plutzky J (1999) PPARalpha activators inhibit cytokine-induced vascular cell adhesion molecule-1 expression in human endothelial cells. Circulation 99: 3125-3131.

27. Reynolds LE, Hodivala-Dilke KM (2006) Primary mouse endothelial cell culture for assays of angiogenesis. Methods Mol Med 120: 503-509.

28. Page P OM, Fioraso-Cartier L, Mottironi B (2008) Pyrazolo pyridine derivatives as NAPDH oxidase inhibitors. Patent WO 2008/113856 A1. In: Genkyotex, ed. Switzerland.

29. Palicz A, Foubert TR, Jesaitis AJ, Marodi L, McPhail LC (2001) Phosphatidic acid and diacylglycerol directly activate NADPH oxidase by interacting with enzyme components. J Biol Chem 276: 3090-3097.
30. Serrander L, Cartier L, Bedard K, Banfi B, Lardy B, et al. (2007) NOX4 activity is determined by mRNA levels and reveals a unique pattern of ROS generation. Biochem J 406: 105-114.

31. Cerep Website: www.cerep.fr (Access 2011). In vitro pharmacological profile was performed at the company Cerep, France.

32. Perry BN, Govindarajan B, Bhandarkar SS, Knaus UG, Valo M, et al. (2006) Pharmacologic blockade of angiopoietin-2 is efficacious against model hemangiomas in mice. J Invest Dermatol 126: 2316-2322.

33. Bhandarkar SS, Jaconi M, Fried LE, Bonner MY, Lefkove B, et al. (2009) Fulvene- 5 potently inhibits NADPH oxidase 4 and blocks the growth of endothelial tumors in mice. J Clin Invest 119: 2359-2365.

34. Goetze S, Eilers F, Bungenstock A, Kintscher U, Stawowy P, et al. (2002) PPAR activators inhibit endothelial cell migration by targeting Akt. Biochem Biophys Res Commun 293: 1431-1437.

35. Meissner M, Stein M, Urbich C, Reisinger K, Suske G, et al. (2004) PPARalpha activators inhibit vascular endothelial growth factor receptor-2 expression by repressing Spl-dependent DNA binding and transactivation. Circ Res 94: $324-332$.

36. Hussain SP, Hofseth LJ, Harris CG (2003) Radical causes of cancer. Nat Rev Cancer 3: 276-285.

37. Liou GY, Storz P Reactive oxygen species in cancer. Free Radic Res 44: $479-496$.

38. Klaunig JE, Kamendulis LM, Hocevar BA Oxidative stress and oxidative damage in carcinogenesis. Toxicol Pathol 38: 96-109.

39. Sadok A, Bourgarel-Rey V, Gattacceca F, Penel C, Lehmann M, et al. (2008) Nox1-dependent superoxide production controls colon adenocarcinoma cell migration. Biochim Biophys Acta 1783: 23-33.

40. Schroder K, Helmcke I, Palfi K, Krause KH, Busse R, et al. (2007) Nox1 mediates basic fibroblast growth factor-induced migration of vascular smooth muscle cells. Arterioscler Thromb Vasc Biol 27: 1736-1743.

41. Lyle AN, Deshpande NN, Taniyama Y, Seidel-Rogol B, Pounkova L, et al. (2009) Poldip2, a novel regulator of Nox4 and cytoskeletal integrity in vascular smooth muscle cells. Circ Res 105: 249-259.

42. Ushio-Fukai M, Tang Y, Fukai T, Dikalov SI, Ma Y, et al. (2002) Novel role of gp91(phox)-containing NAD $(\mathrm{P}) \mathrm{H}$ oxidase in vascular endothelial growth factorinduced signaling and angiogenesis. Circ Res 91: 1160-1167.

43. Harfouche R, Malak NA, Brandes RP, Karsan A, Irani K, et al. (2005) Roles of reactive oxygen species in angiopoietin-1/tie-2 receptor signaling. FASEB J 19: $1728-1730$.

44. Tojo T, Ushio-Fukai M, Yamaoka-Tojo M, Ikeda S, Patrushev N, et al. (2005) Role of gp91phox (Nox2)-containing $\mathrm{NAD}(\mathrm{P}) \mathrm{H}$ oxidase in angiogenesis in response to hindlimb ischemia. Circulation 111: 2347-2355.

45. Diebold I, Djordjevic T, Petry A, Hatzelmann A, Tenor H, et al. (2009) Phosphodiesterase 2 mediates redox-sensitive endothelial cell proliferation and angiogenesis by thrombin via Racl and NADPH oxidase 2. Circ Res 104: 1169-1177.

46. Petry A, Djordjevic T, Weitnauer M, Kietzmann T, Hess J, et al. (2006) NOX2 and NOX4 mediate proliferative response in endothelial cells. Antioxid Redox Signal 8: 1473-1484.

47. Hilenski LL, Clempus RE, Quinn MT, Lambeth JD, Griendling KK (2004) Distinct subcellular localizations of Nox1 and Nox4 in vascular smooth muscle cells. Arterioscler Thromb Vasc Biol 24: 677-683.

48. Martyn KD, Frederick LM, von Loehneysen K, Dinauer MC, Knaus UG (2006) Functional analysis of Nox4 reveals unique characteristics compared to other NADPH oxidases. Cell Signal 18: 69-82.

49. Jaquet V, Scapozza L, Clark RA, Krause KH, Lambeth JD (2009) Smallmolecule NOX inhibitors: ROS-generating NADPH oxidases as therapeutic targets. Antioxid Redox Signal 11: 2535-2552.

50. Shono T, Yokoyama N, Uesaka T, Kuroda J, Takeya R, et al. (2008) Enhanced expression of NADPH oxidase Nox4 in human gliomas and its roles in cell proliferation and survival. Int J Cancer 123: 787-792.

51. Maraldi T, Prata C, Caliceti C, Vieceli Dalla Sega F, Zambonin L, et al. VEGFinduced ROS generation from $\mathrm{NAD}(\mathrm{P}) \mathrm{H}$ oxidases protects human leukemic cells from apoptosis. Int J Oncol 36: 1581-1589.

52. Block K, Gorin Y, New DD, Eid A, Chelmicki T, et al. The NADPH oxidase subunit p22phox inhibits the function of the tumor suppressor protein tuberin. Am J Pathol 176: 2447-2455.

53. Kamata T (2009) Roles of Nox 1 and other Nox isoforms in cancer development. Cancer Sci 100: 1382-1388.

54. Shono T, Ono M, Izumi H, Jimi SI, Matsushima K, et al. (1996) Involvement of the transcription factor NF-kappaB in tubular morphogenesis of human microvascular endothelial cells by oxidative stress. Mol Cell Biol 16: 4231-4239.

55. Yasuda M, Ohzeki Y, Shimizu S, Naito S, Ohtsuru A, et al. (1999) Stimulation of in vitro angiogenesis by hydrogen peroxide and the relation with ETS-1 in endothelial cells. Life Sci 64: 249-258.

56. Luczak K, Balcerczyk A, Soszynski M, Bartosz G (2004) Low concentration of oxidant and nitric oxide donors stimulate proliferation of human endothelial cells in vitro. Cell Biol Int 28: 483-486.

57. Xia C, Meng Q Liu LZ, Rojanasakul Y, Wang XR, et al. (2007) Reactive oxygen species regulate angiogenesis and tumor growth through vascular endothelial growth factor. Cancer Res 67: 10823-10830. 
58. Diebold I, Petry A, Hess J, Gorlach A The NADPH Oxidase Subunit NOX4 Is a New Target Gene of the Hypoxia-inducible Factor-1. Mol Biol Cell.

59. Lambeth JD, Krause KH, Clark RA (2008) NOX enzymes as novel targets for drug development. Semin Immunopathol 30: 339-363.

60. Burns KA, Vanden Heuvel JP (2007) Modulation of PPAR activity via phosphorylation. Biochim Biophys Acta 1771: 952-960.

61. Leuenberger N, Pradervand S, Wahli W (2009) Sumoylated PPARalpha mediates sex-specific gene repression and protects the liver from estrogeninduced toxicity in mice. J Clin Invest 119: 3138-3148.

62. Luciani A, Villella VR, Vasaturo A, Giardino I, Raia V, et al. (2009) SUMOylation of tissue transglutaminase as link between oxidative stress and inflammation. J Immunol 183: 2775-2784.

63. Clerkin JS, Naughton R, Quiney C, Cotter TG (2008) Mechanisms of ROS modulated cell survival during carcinogenesis. Cancer Lett 266: 30-36.

64. Liu RM, Choi J, Wu JH, Gaston-Pravia KA, Lewis KM, et al. Oxidative modification of nuclear mitogen activated protein kinase phosphatase 1 is involved in transforming growth factor betal-induced expression of plasminogen activator inhibitor 1 in fibroblasts. J Biol Chem.

65. Kang SI, Choi HW, Kim IY (2008) Redox-mediated modification of PLZF by SUMO-1 and ubiquitin. Biochem Biophys Res Commun 369: 1209-1214.

66. Bergers G, Hanahan D (2008) Modes of resistance to anti-angiogenic therapy. Nat Rev Cancer 8: 592-603.

67. Paez-Ribes M, Allen E, Hudock J, Takeda T, Okuyama H, et al. (2009) Antiangiogenic therapy elicits malignant progression of tumors to increased local invasion and distant metastasis. Cancer Cell 15: 220-231.
68. Lee SS, Pineau T, Drago J, Lee EJ, Owens JW, et al. (1995) Targeted disruption of the alpha isoform of the peroxisome proliferator-activated receptor gene in mice results in abolishment of the pleiotropic effects of peroxisome proliferators. Mol Cell Biol 15: 3012-3022.

69. Aurrand-Lions M, Johnson-Leger C, Pepper MS, Imhof BA (2004) Haemangiomas are formed by cells expressing high levels of alphavbeta 3 integrin and lacking acetylated LDL uptake. J Pathol 203: 700-709.

70. Montet X, Figueiredo JL, Alencar H, Ntziachristos V, Mahmood U, et al. (2007) Tomographic fluorescence imaging of tumor vascular volume in mice. Radiology 242: 751-758.

71. Montet X, Pastor CM, Vallee JP, Becker CD, Geissbuhler A, et al. (2007) Improved visualization of vessels and hepatic tumors by micro-computed tomography (CT) using iodinated liposomes. Invest Radiol 42: 652-658.

72. Miljkovic-Licina M, Hammel P, Garrido-Urbani S, Bradfield PF, Szepetowski P, et al. (2009) Sushi repeat protein X-linked 2, a novel mediator of angiogenesis. FASEB J.

73. Tauzin S, Ding H, Khatib K, Ahmad I, Burdevet D, et al. (2008) Oncogenic association of the Cbp/PAG adaptor protein with the Lyn tyrosine kinase in human B-NHL rafts. Blood 111: 2310-2320.

74. Aurrand-Lions M, Duncan L, Ballestrem C, Imhof BA (2001) JAM-2, a novel immunoglobulin superfamily molecule, expressed by endothelial and lymphatic cells. J Biol Chem 276: 2733-2741. 